\title{
Program Kursus Bahasa Inggris Gratis “JeepEnglish" sebagai Upaya Meningkatkan Kompetensi Sopir Jeep Wisata
}

\author{
Ari Sulistyo \\ SMP Negeri 1 Tepus \\ ari_cgg@yahoo.com
}

\section{Article History}

accepted 01/12/2020

\begin{abstract}
The ability to communicate in English often becomes an obstacle for tourism actors. This research focused on the free English training program for Timang beach jeep drivers in Tepus, Gunungkidul Regency. The jeep driver community was chosen because they usually meet foreign tourists. The training program was held 5 times with good and smooth results. Some of the success factors of this program are (1) flexibility, based on the situation and needs of the participant, (2) practice, the opportunity practice their new English skills, and (3) consistency, the program must be sustainable and consistent in its implementation.
\end{abstract}

Keywords: training, JeepEnglish, tourism

\begin{abstract}
Abstrak
Kemampuan berkomunikasi dengan bahasa Inggris seringkali menjadi kendala bagi para pelaku wisata. Salah satu upaya yang dapat dilakukan adalah melalui program pelatihan bahasa Inggris gratis bagi para sopir jeep pantai Timang di Kecamatan Tepus, Kabupaten Gunungkidul. Komunitas sopir jeep ini dipilih karena berhubungan langsung dengan wisatawan manca negara. Program pelatihan dilaksanakan sebanyak 5 kali pertemuan dengan hasil lancar dan baik. Beberapa faktor keberhasilan program ini adalah (1) fleksibilitas, sesuai situasi dan kebutuhan di lapangan, (2) praktik, adanya kesempatan untuk praktik langsung, dan (3) konsistensi, program harus berlanjut dan konsisten dalam pelaksanaannya.
\end{abstract}

Kata kunci: pelatihan, JeepEnglish, wisata

Social, Humanities, and Education Studies (SHEs): Conference Series https://jurnal.uns.ac.id/shes 


\section{PENDAHULUAN}

Kabupaten Gunungkidul merupakan bagian dari Daerah Istimewa Yogyakarta yang dikenal sebagai salah satu destinasi pariwisata unggulan di Indonesia. Daerah ini mulai dikenal lebih luas lagi seiring dengan berkembangnya teknologi informasi. Dalam satu dasawarsa terakhir, sektor pariwisata di Gunungkidul berkembang sangat pesat. Hal tersebut ditandai dari jumlah wisatawan, restoran, dan pendapatan daerah dari sektor ini. Berdasarkan data Badan Pusat Statistik Kabupaten Gunungkidul jumlah wisatawan yang mengunjungi Gunungkidul meningkat tajam dari 1.337.438 wisatawan di tahun 2013 menjadi 3.258.013 wisatawan di tahun 2017. Majunya sektor pariwisata tersebut harus didukung oleh infrastruktur dan sarana prasarana yang memadai. Salah satu aspek penting yang mendukung pariwisata adalah kemampuan berkomunikasi dengan bahasa Inggris para pelaku wisata. Biaya yang mahal, waktu dan jarak menjadi kendala bagi mereka untuk mengikuti kursus bahasa Inggris. Selain itu, latar belakang mereka yang mayoritas hanya lulus pendidikan dasar menambah kendala penguasaan bahasa Inggris. Hal ini juga terjadi di Gunungkidul, para pelaku wisata terkendala minimnya warga yang bisa berkomunikasi dengan bahasa Inggris.

Seperti telah disampaikan di atas kemampuan berkomunikasi dengan bahasa Inggris menjadi kendala bagi para pelaku wisata di Daerah Istimewa Yogyakarta khususnya di Kabupaten Gunungkidul. Padahal dalam lima tahun terakhir ini pariwisata di daerah ini berkembang sangat pesat. Selain meningkatkan pendapatan daerah, majunya pariwisata ini memberikan efek domino bagi warga Gunungkidul yang selama ini dikenal berada di bawah garis kemiskinan. Hadirnya wisatawan mampu membantu perekonomian warga melalui berbagai sektor antara lain penginapan, restoran, jasa wahana wisata, jasa parkir, jasa transportasi (jeep wisata), jasa sewa tikar dan payung, jasa foto dan sebainya. Selain itu pariwisata juga mampu memberikan pekerjaan pagi para pemuda dan mereka yang menganggur atau putus sekolah. Oleh karena itu sangat penting untuk membuat wisatawan nyaman, terkesan dan kemudian kembali lagi. Kenyamanan wisatawan tersebut akan didukung jika mereka mendapat pelayanan yang memuaskan dan salah satunya adalah melalui komunikasi yang lancar. Dalam hal ini penguasaan bahasa Inggris menjadi mutlak diperlukan demi mendukung lancarnya komunikasi para pelaku wisata dengan turis manca negara.

Sebagai salah satu kaum terdidik atau insan pendidikan yang tinggal dan bekerja di daerah tersebut, penulis merasa memiliki tanggung jawab untuk berbuat sesuatu yang bermanfaat untuk membantu mengatasi permasalahan tersebut. Penulis adalah guru bahasa Inggris sehingga hal-hal yang berkaitan dengan bahasa Inggris dan pembelajarannya telah menjadi bidang keahlian penulis. Oleh karena itu, penulis berusaha menyusun sebuah program pelatihan bahasa Inggris untuk para pelaku wisata di Kabupaten Gunungkidul. Program tersebut diharapkan dapat membantu mereka dalam menguasai bahasa Inggris. Penulis melakukan observasi awal dengan cara mendatangi beberapa obyek wisata dan berdiskusi dengan beberapa pihak. Berdasarkan 
observasi dan wawancara singkat dengan beberapa narasumber di lokasi, didapatkan beberapa kesimpulan antara lain:

1. Penguasaan bahasa Inggris sangat diperlukan terutama bagi para pelaku wisata yang langsung berhubungan dengan wisatawan mancanegara seperti sopir jeep wisata, penjaga loket retribusi, pelayan warung makan dan penyewaan jasa payung dan tikar.

2. Saat ini hampir semua pelaku wisata di Gunungkidul sangat lemah dalam berkomunikasi dengan bahasa asing terutama bahasa Inggris. Hal ini disebabkan terutama karena faktor pendidikan yang mereka miliki yaitu hanya lulus jenjang pendidikan dasar saja.

3. Para pelaku wisata menilai bahwa penguasaan bahasa Inggris itu sangat penting dalam membantu berkomunikasi dengan wisatawan mancanegara.

4. Bahasa Inggris yang ingin dikuasai adalah bahasa Inggris 'praktik' atau bahasa Inggris aktif dan komunikatif yang langsung dipakai dan mudah dipelajari.

5. Waktu belajar atau pelatihan yang diharapkan tidak bersamaan dengan waktu kerja atau saat siang hari. Mereka menginginkan pelatihan diadakan malam hari.

6. Para pelaku wisata berharap pelatihan tidak hanya sekedar teori tetapi juga diberikan kesempatan untuk melakukan praktik langsung sehingga mereka memiliki rasa percaya diri.

7. Kendala yang dihadapi selain faktor kemampuan bahasa adalah rasa tidak percaya diri, minder dan takut salah.

Hal-hal di atas sejalan dengan teori dari Joseph, et.al dalam Damayanti (2019) menyebutkan 6 peran penting Bahasa Inggris dalam dunia pariwisata antara lain;

1. Communicative/Interactive Role

Bahasa Inggris merupakan media komunikasi antara pelaku wisata dengan wisatawan maupun antar wisatawan. Pada suatu obyek wisata, bahasa asal ataupun bahasa lokal tidak dapat lagi digunakan karena akan sulit dipahami satu sama lain. Maka pelaku wisata dan wisatawan perlu menggunakan sebuah bahasa yang kedua belah pihak ketahui.

2. Integrative Role

Selain sebagai alat untuk berkomunikasi, bahasa Inggris juga diangkap sebagai pemersatu atas berbagai perbedaan yang ada seperti negara, adat, budaya, ras, dan kepentingan. Dalam hal ini bahasa Inggris mengambil peran dalam mengintegrasikan semua orang tanpa mengenal latar belakang orang-orang tersebut.

\section{Lingua-Franca Role}

Banyak wisatawan yang berkunjung ke lebih dari satu negara dan akan menjadi hal yang sulit jika ia harus belajar bahasa lokal di tiap-tiap negara yang dia kunjungi. Oleh karena itu bahasa Inggris menjadi jembatan komunikasi antara wisawatan tersebut dengan para pelaku jasa wisata.

\section{Relation-Fostering Role}

Dalam hal ini bahasa Inggris dapat berperan dalam proses memperkuat hubungan antar manusia, khususnya hubungan yang bersifat global. Dalam 
dunia pariwisata, Bahasa Inggris memungkinkan wisatawan turut serta dalam kegiatan atau aktivitas masyarakat lokal.

5. Economic/Business Role

Bahasa Inggris sangat besar dalam hal bisnis dan ekonomi. la menjadi menjadi pengantar dalam bisnis, khususnya dalam bisnis pariwisata.

6. Fuctional Role

Peran terakhir Bahasa Inggris dalam dunia pariwisata adalah functional role yaitu membantu wisatawan maupun masyarakat lokal dalam memperoleh informasi tertentu, meminta bantuan, dan fungsi-fungsi lain yang diperlukan dalam kegiatan berwisata.

Berdasarkan data awal dan teori di atas, penulis mencoba menyusun program yang sesuai dan menjadi solusi terhadap masalah yang dihadapi seperti jarak, finansial, waktu, dan materi. Program tersebut diberi judul "JeepEnglish" yaitu pelatihan bahasa Inggris untuk para pengemudi atau sopir Jeep Wisata Pantai Timang.

\section{HASIL DAN PEMBAHASAN}

Program "JeepEnglish" adalah pelatihan bahasa Inggris untuk para pengemudi atau sopir Jeep Wisata Pantai Timang. Komunitas jeep wisata pantai Timang ini dipilih atas beberapa pertimbangan, antara lain; (1) pantai Timang merupakan salah satu destinasi wisata yang paling banyak dikunjungi oleh wisatawan mancanegara, (2) terdapat lebih dari 20 pengemudi sopir jeep wisata di pantai ini, (3) jarak antara pantai ini dengan kota Yogyakarta sangat jauh yaitu sekitar $75 \mathrm{~km}$ yang menyulitkan para sopir jeep jika ingin mengikuti kursus bahasa Inggris di lembaga terpercaya, serta (4) latar belakang pendidikan dari para sopir jeep tersebut sebagian besar hanya lulus pendidikan dasar (SD \& SMP) dan mereka tidak melanjutkan sekolah. Program JeepEnglish ini dilakukan setiap akhir pekan (malam hari), siswa diberikan modul belajar yang disusun khusus dan menyesuaikan kebutuhan mereka, guru atau pengajar datang langsung ke lokasi (basecamp) para sopir jeep tersebut dan adanya pendampingan personal melalui alat komunikasi Whatsapp dimana para sopir jeep dapat berkonsultasi dengan pengajar/tentor setiap saat.

Program JeepEnglish telah dilaksanakan pada bulan Desember 2018 dengan lokasi di Basecamp Jeep Adventure Gunung Kidul, Dusun Pringsanggar, Desa Purwodadi, Kec. Tepus, Kab. Gunung Kidul DIY. Peserta yang telibat sekitar 14-16 sopir Jeep Wisata. Berikut adalah deskripsi beberapa pertemuan pelatihan JeepEnglish yang sudah dilakukan. 1 .

Pertemuan 1 (Sabtu, 01 Desember 2018 pukul 19:30-21.00). Pertemuan ini diawali dengan perkenalan mengenai program pelatihan. Hadir dalam pertemuan ini antara lain ketua kelompok sopir jeep wisata Jeep Adventure (Agus Tara), inisiator program (Ari Sulistyo), tutor pelatihan (Arifina Santiatmaja, S.Pd) dan 16 peserta pelatihan yakni sopir jeep wisata. Pada pertemuan pertama ini, materi yang dibahas adalah perkenalan (introduction), cara menyapa (greeting), dan cara menawarkan jasa (offering service). Para peserta pelatihan sangat antusias mengikuti pembelajaran meskipun mereka mengalami kendala terkait dengan daya ingat dan penguasaan kosakata (vocabulary) dan pelafalan kata dalam bahasa Inggris (pronunciation). Hal tersebut terjadi karena sebagian besar dari peserta pelatihan hanya lulusan SMP yang tidak memiliki dasar-dasar pemahaman bahasa Inggris. Tutor memfokuskan aktivitas pada praktek berbicara. 
Setiap siswa diberikan kesempatan untuk mencoba dan praktik berbahasa Inggris. Kegiatan berjalan cukup lambat tetapi menuai hasil yang cukup memuaskan.

Pertemuan 2 (Minggu, 09 Desember 2018 pukul 19.30-21.00). Rencana pertemuan Sabtu terpaksa diundur karena para sopir Jeep sedang mendapat banyak tamu dan sebagian besar sampai malam. Dalam pertemuan ini jumlah peserta pelatihan menurun dibandingkan pada pertemuan pertama. Pada pertemuan ini, materi yang dibahas adalah Angka (Number). Topik ini dianggap penting karena dengan belajar tentang angka dalam bahasa Inggris, peserta akan memahami mengenai nomor telepon, harga, penjumlahan dasar, dan waktu. Ternyata para peserta masih kesulitan menghapal dan melafalkan nama-nama angka dalam bahasa Inggris. Beberapa siswa lain yang memiliki pendidikan SMA cenderung tidak mengalami kesulitan dalam menguasai topik ini. Kali ini tutor menggunakan metode permainan (games) agar para peserta tidak bosan.

Pertemuan 3 (Sabtu, 15 Desember 2018 pukul 19.30 - 21.00). Dalam pertemuan ini jumlah peserta masih tetap sama dibandingkan pada pertemuan sebelumnya. Kali ini tema yang dibahas adalah pertanyaan dan kosakata yang berhubungan dengan pariwisata pantai Timang. Para siswa sangat termotivasi karena mereka dapat mengaitkan langsung dengan situasi yang dihadapi langsung di lapangan. Salah satu peserta bahkan dengan bangga bercerita bahwa hari itu ia telah mencoba mempraktekkan bahasa Inggris dengan tamu asing. la sangat senang ketika tamu tersebut memahami kata-katanya.

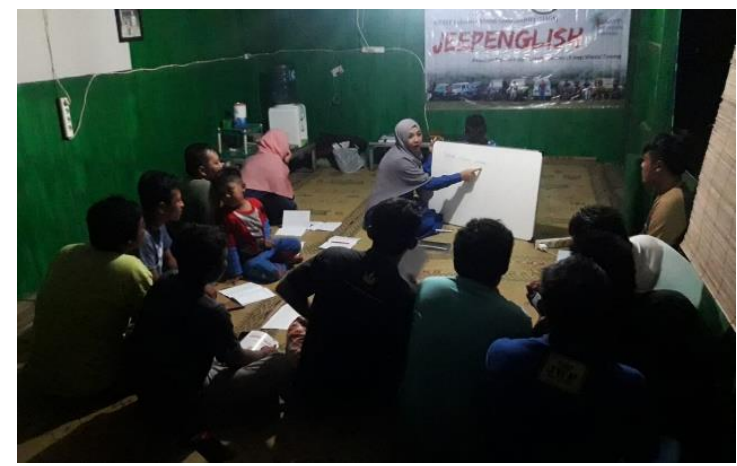

\section{Gambar 1. Kegiatan Pelatihan Bahasa Inggris Program “JeepEnglish”}

Pertemuan 4 (Sabtu, 22 Desember 2018). Dalam pertemuan ini para sopir jeep diberikan kesempatan untuk melakukan praktek komunikasi berupa simulasi. Selain itu, mereka melakukan refleksi dan evaluasi diri dalam kaitannya dengan pelatihan bahasa Inggris ini. Para sopir jeep tersebut sangat antusias untuk bertanya terutama hal-hal yang berkaitan dengan kosakata dan kebiasaan wisatawan mancanegara. Dalam pertemuan ini lebih banyak dilakukan Q\&A dengan tutor.

Pertemuan 5 (Minggu, 19 Mei 2019 berupa praktik lapangan). Pertemuan ini berupa praktik lapangan yakni para peserta program diberikan kesempatan untuk praktik bahasa Inggris langsung dengan wisatawan asing. Inisiator program bekerjasama dengan Stichting Jogja menghadirkan Demi Rietveld dan Joanne van der Vlist dari Belanda untuk melakukan praktik langsung dengan para sopir jeep tersebut. Demi dan Joanne kemudian diajak naik Jeep ke pantai Timang untuk mencoba wahana Gondola dengan dipandu oleh sopir Jeep. Setelah dari pantai Timang, tamu turis asing tersebut diajak untuk mencoba kuliner lobster. 


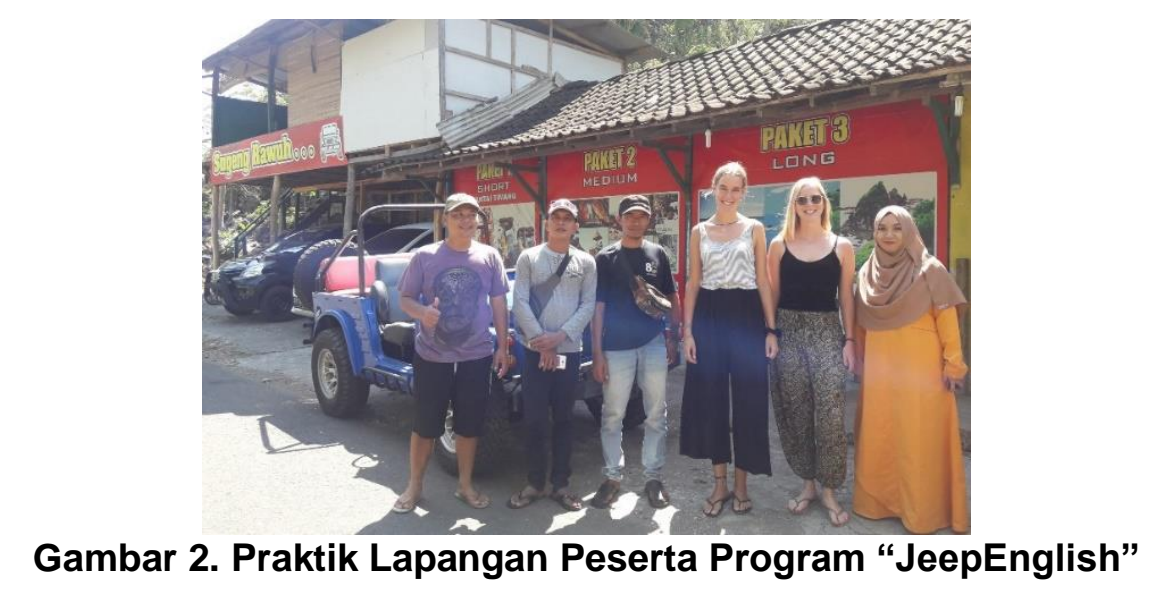

\section{SIMPULAN}

Secara umum program ini terlaksana dengan baik dan lancar. Hal tersebut diukur dari antusiasme peserta, proses dan hasil yang diharapkan. Adapun kendala yang dihadapi antara lain; (1) sulitnya mencari tentor bahasa Inggris yang bersedia untuk mengajar di malam hari di lokasi basecamp sopir Jeep yang jauh dari kota Yogyakarta, (2) sulitnya menghadirkan turis asing untuk praktik langsung dengan para sopir Jeep, dan (3) kurangnya kekompakan para sopir Jeep dimana di pantai Timang terdapat beberapa komunitas Jeep yang satu sama lain ternyata kurang kompak dan cenderung bersaing tidak sehat. Hal ini berimbas pada jumlah peserta program. Inisiator program telah mengundang para sopir Jeep dari berbagai kelompok namun mereka tidak hadir.

Adapun beberapa rekomendasi yang diusulkan antara lain; (1) sebaiknya program pelatihan tersebut dapat bekerja sama dengan birokrasi sehingga dapat "diatasnamakan" birokrasi tersebut, misalnya atas nama pemerintah desa yang mengundang para sopir Jeep sehingga lebih memiliki "bargaining position" (2) perlu adanya terobosan, niat dan inisiasi dari para insan pendidikan atau kaum akademisi agar lebih peka dan peduli dengan masalah di sekitar kita sesuai kebutuhan dan sikon yang ada, misalnya guru bahasa Inggris dapat mengembangkan pelatihan bahasa Inggris gratis untuk para pelaku wisata, guru IPA dapat membantu kesulitan belajar anak-anak di lingkungannya meskipun bukan siswa di sekolahnya, guru Agama dapat menginisiasi program pelatihan baca tulis quran di masjid tempat tinggalnya, dan lain-lain, (3) perlu adanya kerja sama dengan para lembaga donor sepert AAI, SII, UNESCO, dan lain-lain untuk mewujudkan pelatihan-pelatihan tersebut, dan (4) hendaknya program tersebut digelar tidak hanya 1-2 hari saja tetapi berkelanjutan sehingga perkembangan kemampuan peserta dapat dipantau.

\section{DAFTAR PUSTAKA}

Iriance, I. (2018). Bahasa Inggris Sebagai Bahasa Lingua Franca dan Posisi Kemampuan Bahasa Inggris Masyarakat Indonesia Diantara Anggota MEA. Prosiding Industrial Research Workshop and National Seminar, 9 (0), 776-783. Dikutip dari https://jurnal.polban.ac.id/index.php/proceeding/article/view/1149/944

Damayanti, Sri. 2019. Peranan Keterampilan Berbahasa Inggris dalam Industri Pariwisata. Journey: Volume 2. Nomor 01, Desember 2019 diakses Kamis, 17 Desember 2020 jam 17.50 wib.

Dinas Pariwisata DIY. 2019. Statistik Kepariwisataan 2019, Yogyakarta: Dinas Pariwisata DIY. 
SHEs: Conference Series 4 (2) (2021) $11-17$

Badan Pusat Statistik Kab. Gunungkidul. 2019. Gunungkidul Dalam Angka 2019. Gunungkidul: BPS.

Suluh Pamungkas, "Wabup Gunungkidul Dorong Pelaku Wisata Gunakan Bahasa Inggris pada Wisatawan Asing" https://jogja.tribunnews.com/2019/09/07/wabupgunungkidul-dorong-pelaku-wisata-gunakan-bahasa-inggris-pada-wisatawanasing. (Diakses 16 Desember 2020, pukul 18.40 wib). 